Patrick Joseph L. Estolano, MD Antonio H. Chua, MD
Correspondence: Dr. Antonio H. Chua

Department of Otorhinolaryngology - Head and Neck Surgery Jose R. Reyes Memorial Medical Center

San Lazaro Compound, Rizal Avenue, Sta. Cruz, Manila 1003 Philippines

Phone: (632) 743 6921; (632) 7119491 local 320

Email:entjrrmmc@yahoo.com

Reprints will not be available from the authors.

The authors declared that this represents original materia that is not being considered for publication or has not been published or accepted for publication elsewhere in full or in part, in print or electronic media; that the manuscript has been read and approved by the authors, that the requirements for authorship have been met by the authors, and that the authors believe that the manuscript represents honest work.

Disclosures: The authors signed disclosures that there are no financial or other (including personal) relationships, intellectual passion, political or religious beliefs, and institutional affiliations that might lead to a conflict of interest.

Presented at Philippine Society of Otolaryngology Head and Neck Surgery Descriptive Research Contest, September 18, 2014. Natrapharm, The Patriot Bldg., KM 18 SLEX, Paranaque City.

\title{
Spontaneous Passage of Ingested Coin in Children
}

ABSTRACT
Objective: To determine the factors related to spontaneous passage of ingested coins in children.

\section{Methods:}

Design: Retrospective study

Setting: Tertiary Government Hospital

Subjects: The records of 136 pediatric patients with a history of coin ingestion seen at the emergency room department of our institution between December 2012 and May 2014 were retrospectively reviewed. Demographic data such as age and gender of the patient were recorded, including the type of coin, location of coin in the esophagus, time of ingestion and time of spontaneous passage into the stomach (for those that passed spontaneously).

Results: Spontaneous passage in 27 out of 136 pediatric patients with radiographic evidence of a round radio-opaque foreign body initially located in the esophagus eventually passed into the stomach or intestines, accounting for $20 \%$ of the total number of cases. Coin ingestion was more common in patients aged 5 to 6 years (33\% of cases), with slight male predominance (58\%). One peso coins were the most common type of coin ingested, however only $24 \%$ of these spontaneously passed. The rate of spontaneous passage was highest in smaller sized coins ( 5 and 25 centavo coin) compared to larger sized coins (5 peso). Proximally located coins, albeit more common than middle and distally located coins, were the least likely to spontaneously pass (12\%). Average time interval from ingestion to passage of the coin was 12 hours.

Conclusion: Many factors are related to spontaneous passage of foreign bodies in the esophagus. The age of the patient, type of coin ingested, and initial location of the coin in the esophagus should be considered. Older patients, smaller sized coins, and distally located coins have the highest probability of spontaneous passage beyond the esophagus. A 12-hour observation period may be considered in patients with single esophageal coin ingestion.

Keywords: foreign body, esophagus, esophagoscopy

In children, the most common foreign body ingested are coins, comprising $75 \%$ of all cases. ${ }^{1}$ The decision whether to first observe or operate on pediatric patients has been discussed in several articles. ${ }^{2-6}$

Philipp J Otolaryngol Head Neck Surg 2015; 30 (2): 30-33

(C) Philippine Society of Otolaryngology - Head and Neck Surgery, Inc 
Several surgical procedures for the removal of esophageal foreign bodies have been proposed and are currently in use, ranging from the use of a Foley catheter, bougienage, and esophageal dilators to flexible esophagoscopy for retrieval of blunt foreign bodies. Careful endoscopic removal of foreign bodies under direct visualization by rigid esophagoscopy is the safest management for patients with foreign body ingestion. ${ }^{1}$ However, complications from this "safe" intervention may also arise, the most common of which is respiratory distress occurring during the procedure.' This may result from accidental dislodging of the endotracheal tube. ${ }^{1}$ Other possible complications such as esophageal perforation, retroesophageal abscess, mediastinitis and death can occur, but these are rare. ${ }^{1}$

Several studies show that there is a high rate of spontaneous passage of esophageal coins into the stomach..$^{1-6}$ Soprano et al. reported an incidence of spontaneous passage of esophageal coins as high as $28 \%$. $^{2}$ They suggested that a 12 - to 24 -hour observation period should be given among children with single esophageal coin ingestion, with no history of esophageal disease and no respiratory compromise on presentation. ${ }^{2}$ Waltzman et al. reported factors that may predict spontaneous passage of esophageal coins, including the initial location in the distal esophagus, male gender, and age older than 5 -years-old. ${ }^{3}$ They suggested that an observation period of 8 to 16 hours is appropriate in otherwise healthy children with asymptomatic esophageal coins. ${ }^{3}$

However, prolonged observation for spontaneous passage can also lead to several complications. Complications arise when there is prolonged obstruction leading to inflammation and edema of the surrounding tissue, resulting in ischemia and eventual erosion and esophageal perforation which may lead to several life-threatening complications.' These may present as hemoptysis, pneumonia, atelectasis, abscess formation, or fever.'

In order to avoid such complications, early detection and decision on whether to observe for spontaneous passage or initiate surgical intervention is required. In our institution, there are no guidelines on when to watchfully wait for spontaneous passage and when to proceed with surgery. This study aims to identify the factors affecting spontaneous passage of ingested coins in children.

\section{METHODS}

Study Design: Retrospective study

Setting: Tertiary Public Hospital

Subjects: With institutional ethical review board approval, the medical records of 136 pediatric patients less than 18-years of age with a history of coin ingestion seen at the emergency room department of our institution between December 2012 and May 2014, were retrospectively reviewed. Demographic factors of the patients such as age and gender were recorded. Similarly, the type of coin ingested, time of ingestion, time of spontaneous passage beyond the esophagus (for those that passed spontaneously), and initial location of the coin in the esophagus (proximal, middle, distal third) were tabulated. Initial diagnosis of the coin in the esophagus and spontaneous passage were confirmed through radiography.

Data and Statistical Analysis: The mean age, gender ratio, age distribution, mean time interval between coin ingestion and passage beyond the esophagus were computed from the data gathered. The percentage of cases that spontaneous passed into the esophagus per age group, gender, type of coin, and location in the esophagus, were likewise determined.

\section{RESULTS}

During the 18 month period, a total of 136 pediatric patients (79 or $58 \%$ male, 57 of $42 \%$ female) consulting at the Emergency Department with pertinent complaints were diagnosed with coin ingestion located in the esophagus at the time of consult. Spontaneous passage beyond the esophagus was observed in 27 children (20\%). Of these, 16 were male (59\%) and 11 were female (41\%).

Coin ingestion was more common in the 5- to 6-year-old age group, comprising 45 out of the 136 patients (33.1\%). The highest percentage of coin passage was seen in the older age group, in one patient 14 to 16 years of age-- a $100 \%$ spontaneous passage rate (1 out 1 patient). On the other hand, patients aged 0 to 2 years had the lowest percentage of spontaneous coin passage into the Gl tract ( 2 of the 18 cases, $11 \%$ ). (Table 1) For the cases in which spontaneous passage was observed, the youngest patient was 11 months old, and the oldest was 16 years old.

Table 2 shows the percentage of coins that spontaneously passed per type of coin ingested. One-peso coins were the most commonly ingested coins encountered (97 out of 136 cases), with a spontaneous passage rate of $24 \%$. The highest percentage of spontaneous passage was seen in the case of 5 centavo and 25 centavo coins, having a 100\% spontaneous passage rate. On the other hand, only 1 out of the 11 ingested 5 peso coins spontaneously passed beyond the esophagus (9\%). No data regarding the type of coin swallowed was retrieved for 24 cases.

Proximally located coins comprised the majority of cases of coin ingested during the 18 month study period, accounting for 110 out of the total 136 cases (81\%). However, the passage rate in this group was only $12 \%$. On the other hand, despite having the lowest number of cases (8 of the 136 cases $-5.9 \%$ ), coins located in the distal third of the esophagus had a $75 \%$ spontaneous passage rate ( 6 out of 8 patients with distally-located coins). Coins located in the middle third of the 
esophagus had a passage rate of $44 \%$ (8 out of the 18 cases). (Table 3 )

The mean average time from ingestion to passage of the coin lodged in any segment of the esophagus was 12.4 hours (range $2-72$ hours).

Table 1. Spontaneous Passage of Coins per Age Group

\begin{tabular}{|l|c|c|c|}
\hline Age (years) & $\begin{array}{c}\text { Number of Cases } \\
\text { of Esophageal } \\
\text { Coin Ingestion } \\
\text { (n= 136) }\end{array}$ & $\begin{array}{c}\text { Number of Cases } \\
\text { with Spontaneous } \\
\text { Passage } \\
\text { of Coin } \\
\text { (n= 27) }\end{array}$ & $\begin{array}{c}\text { Percentage } \\
\text { of Cases that } \\
\text { Spontaneously } \\
\text { Passed } \\
\text { (\%) }\end{array}$ \\
\hline Birth to 2 & 18 & 2 & 11 \\
\hline 3 to 4 & 36 & 5 & 14 \\
\hline 5 to 6 & 45 & 10 & 22 \\
\hline 7 to 8 & 20 & 4 & 20 \\
\hline 9 to 10 & 12 & 2 & 17 \\
\hline 11 to 12 & 4 & 3 & 75 \\
\hline 13 to 14 & - & - & - \\
\hline 14 to 16 & 1 & 1 & 100 \\
\hline 17 to 18 & - & - & - \\
\hline
\end{tabular}

Table 2. Spontaneous Passage per Type of Coin

\begin{tabular}{|l|c|c|c|}
$\begin{array}{c}\text { Type of } \\
\text { Coin } \\
\text { Ingested }\end{array}$ & $\begin{array}{c}\text { Number of Cases } \\
\text { of Esophageal } \\
\text { Coin Ingestion } \\
(\mathbf{n}=\mathbf{1 3 6})\end{array}$ & $\begin{array}{c}\text { Number of Cases } \\
\text { with Spontaneous } \\
\text { Passage of Coin } \\
(\mathbf{n = 2 7})\end{array}$ & $\begin{array}{c}\text { Percentage } \\
\text { of Cases that } \\
\text { Spontaneously } \\
\text { Passed } \\
\mathbf{( \% )}\end{array}$ \\
\hline 5 centavo & 1 & 1 & 100 \\
\hline 10 centavo & 2 & 1 & 50 \\
\hline 25 centavo & 1 & 1 & 100 \\
\hline 50 centavo & 0 & 0 & - \\
\hline 1 Peso & 97 & 23 & 24 \\
\hline 5 Peso & 11 & 1 & 9 \\
\hline $\begin{array}{l}\text { Undetermined } \\
\text { Type }\end{array}$ & 24 & 0 & 0 \\
\hline
\end{tabular}

Table 3. Spontaneous Passage of Coin per Initial Location in Esophagus

\begin{tabular}{|l|c|c|c|}
\hline Location: & $\begin{array}{c}\text { Number of Cases } \\
\text { of Esophageal } \\
\text { Coin Ingestion } \\
\mathbf{n = 1 3 6}\end{array}$ & $\begin{array}{c}\text { Number of Cases } \\
\text { with Spontaneous } \\
\text { Passage of Coin } \\
\mathbf{n = 2 7}\end{array}$ & $\begin{array}{c}\text { Percentage } \\
\text { of Cases that } \\
\text { Spontaneously } \\
\text { Passed } \\
\text { (\%) }\end{array}$ \\
\hline Proximal third & 110 & 13 & 12 \\
\hline Middle third & 18 & 8 & 44 \\
\hline Distal third & 8 & 6 & 75 \\
\hline
\end{tabular}

\section{DISCUSSION}

Most cases of foreign body ingestion involve the pediatric age group, a majority occurring between the ages of 1 to 3 years. ${ }^{1}$ Pediatric patients are susceptible to accidental foreign body ingestion at this age because they curiously tend to explore the environment by placing objects in their mouth, and they often run or play with objects in their mouth, causing accidental swallowing. ${ }^{1}$ Of the 136 patients seen and diagnosed with coin ingestion in our study, the majority of cases belonged to the 5- to 6-year-old age group, comprising 33\% of total cases, with male patients being more commonly involved than females ( $58 \%$ and $42 \%$ respectively). These results are similar to the other studies where most of the patients were toddlers and preschoolers. $^{2,3,5}$

In terms of age, older patients had a higher chance of spontaneous coin passage into the stomach, with the highest percentage seen in the older age group of 14 - 16 years (100\% passage rate), followed by those aged 11 to 12 years old (75\% passage). On the other hand, the lowest percentage of coin passing was seen in patients younger than 3 years of age, having a passage rate of only $11 \%$. These reflect the findings of Waltzmann et al., who concluded that spontaneous passage of ingested coin tends to increase as the patient gets older, noting that incidence of spontaneous passage was higher in patients older than 5 years of age. ${ }^{3}$

In our study, larger sized 5 peso coins (diameter $27 \mathrm{~mm}$ ) were less likely to spontaneously pass compared to smaller diameter, 5 centavo $(15.5 \mathrm{~mm})$ and 25 centavo $(20 \mathrm{~mm})$ coins. The size of the foreign body is inversely related to the probability of the coin passing through the esophageal constrictions and lumen.

We observed that the mean time interval from time of ingestion to time of passage beyond the esophagus was 12.4 hours, regardless of the segment where the coin was initially located. Similar studies such as that of Stringer and Capps showed spontaneous passage of the coin 12 hours post-ingestion in 33\% of cases. ${ }^{4}$ This was also observed by Soprano et al. who suggested an observation period of 12 - 24 hours from the time of coin ingestion in asymptomatic patients with a simple case of coin ingestion (i.e. no history of esophageal disease or surgery) prior to performing an invasive procedure. ${ }^{2}$ Their study concluded that there is a $28 \%$ chance of spontaneous passage of the coin into the stomach. $^{2}$

The most common area where foreign bodies lodge is the cervical esophagus, particularly the area just below the cricopharyngeus muscle. ${ }^{1}$ This was likewise observed in our study wherein 110 out of the 136 coins lodged in the proximal third of the esophagus (81\% of cases). On the other hand, coins that lodged in the middle and distal third was less commonly encountered in our study, occurring in $44 \%$ and $6 \%$ of the cases respectively. Obstruction in this part of the esophagus is often 
caused by extra-luminal compression by the aortic arch or the left main stem bronchus. ${ }^{1}$

In terms of location, the area from where spontaneous passage of the coin most occurred was the distal third of the esophagus-with a passage rate of $75 \%$. In contrast, the proximal third of the esophagus (which was the most common area where ingested foreign bodies lodged) had the lowest rate of spontaneous passage of coins (12\%), while the middle third had a $44 \%$ spontaneous passage rate. The low passage rate of coins from the proximal third of the esophagus may be attributed to the area of the cricopharyngeal muscle, which corresponds to the first anatomic constriction of the esophagus. In general, our study found a $20 \%$ spontaneous passage rate of coins beyond the esophagus regardless of initial location.

Treatment options in patients with foreign body ingestion are controversial. Performing outright surgery versus observation for spontaneous passage has been debated, giving rise to numerous studies on rates of spontaneous passage of ingested foreign bodies. ${ }^{2-6}$ Conners et al., suggest that the decision whether to operate or observe first depends on the initial location of the coin in the esophagus. ${ }^{5}$ They suggested that immediate surgical intervention is warranted in patients with esophageal coins lodged in the proximal and middle third. ${ }^{5}$ According to their study, none of the coins lodged in these segments passed. On the other hand, coins situated in the distal part of the esophagus can be observed for a period of 24 hours for the possibility of the coin to pass on its own..$^{5}$ As much as $60 \%$ of cases of distal esophageal coin obstruction passed spontaneously after observation. ${ }^{5}$

Contrary to Conners et al., Soprano et al.suggested that a 12 to 24 hour observation period should still be implemented even for coins lodged in the proximal and middle third of the esophagus as spontaneous passage may still occur (22\% and $33 \%$ of cases, respectively). ${ }^{2}$ Similarly, Caravati et al. reported a high spontaneous passage rate of $77 \%$ of coins lodged in the esophagus. ${ }^{6}$

Complications from prolonged esophageal foreign body obstruction include formation of true / false esophageal fistulas, aorticoesophageal fistula, esophageal perforation leading to foreign body migration to surrounding structures, esophageal stricture formation, and respiratory distress. ${ }^{8-10}$ However, recent studies reported that observation for $<24$ hour periods have not led to any adverse complications., ${ }^{2,3}$ Soprano et al. reported no adverse events during the observation periods, but noted adverse events during or after endoscopic procedures, including pharyngeal bleeding, bronchospasm, accidental extubation, stridor and hypoxia. ${ }^{2}$ In our study, no adverse reactions or complications were encountered from time of ingestion to time of passage of the coin.

Withholding immediate surgical intervention and opting for more conservative management such as observation in an otherwise asymptomatic patient has been advocated in several studies. ${ }^{2-4}$ However, initial observation for patients with asymptomatic coin ingestion has not been generally accepted, as most parents would opt for immediate removal of the foreign body. ${ }^{11}$ This issue should be wellexplained to the caregivers prior to deciding whether to observe first or perform surgery.

In summary, many factors affect spontaneous passage of an esophageal coin, and no single factor can predict whether a coin will pass beyond the esophagus or remain lodged in it. Factors associated with a greater possibility of spontaneous passage of esophageal coin include age older than 5 years (the older the patient, the higher the possibility for spontaneous passage), smaller sized coins ( 5 centavo and 25 centavo coins) and location in the distal third of the esophagus. In an otherwise asymptomatic and stable pediatric patient with a history of coin ingestion, an observation period of 12 hours from the time of ingestion may be recommended due to the possibility of spontaneous passage beyond the esophagus. Repeat radiography after the allotted observation period is generally recommended to identify the location and/or document passage of the coin. The parent/guardian's informed consent is important prior to recommending any plan of management for a patient with foreign body ingestion.

\section{REFERENCES}

1. Holinger LD, Poznanovic SA. Foreign Bodies of the Airway and Esophagus. In. Flint PW, Haughey $\mathrm{BH}$, Lund VL, NIparko JK, Richardson MA, Robbins KT, et al., editors. Cummings Otolaryngology Head and Neck Surgery $5^{\text {th }}$ Edition. Philadelphia: Mosby Elsevier.2010. p. $2935-2947$.

2. Soprano JV, Fleisher GR, Mandl KD: The spontaneous passage of esophageal coins in children. Arch PediatrAdolesc Med. 1999 Oct; 153(10):1073 - 1076.

3. Waltzman ML, Baskin M, Wypij D, Mooney D, Jones D, Fleisher, G. A randomized clinical trial of the management of esophageal coins in children. Pediatrics 2005 Sep; 116(3):614-9.

4. Stinger MD, Capps SN. Rationalising the management of swallowed coins in children. BMJ. 1991 Jun; 302(6788): 1321-322.

5. Conners GP, Chamberlain JM, Ochsenschlager DW. Symptoms and spontaneous passage of esophageal coins. Arch Pediatr Adolesc Med. 1995 Jan; 149(1): 36 - 39.

6. Caravati EM, Bennett DL, McElwee NE. Pediatric coin ingestions: a prospective study on the utility of routine roentogenograms. Am J Dis Child. 1989 May; 143(5): 549 - 551.

7. Snell RS, Taylor C, Horvath K, Sanders V, Montalbano J, Smock D, et al. The Thorax: Part 1: The Thoracic Wall.Clinical Anatomy by Regions, $8^{\text {th }}$ edition. Philadephia: Lipincott Williams \& Wilkins. 2008.

8. Nahman BJ, Mueller CF. Asymptomatic esophageal perforation by a coin in a child. Ann Emerg Med. 1984 Aug; 13(8):627 - 629.

9. Doolin EJ. Esophageal stricture - an uncommon complication of foreign body. Ann Otol Rhinol Laryngol. 1993 Nov; 102(11): 863 - 866.

10. Dahiya M, Denton JS. Esophagoarotic perforation by foreign body (coin) causing sudden death in a 3 year old child. Am J Forensic Med Pathol. 1999 Jun; 20(2):184-188.

11. Conners GP, Cobaugh DJ, Feinberg R, Lucanie R, Caraccio T, Stork CM. Home observation for asymptomatic coin ingestion: acceptance and outcomes. The New York State Prison Control Center Coin Ingestion Study Group. Acad Emerg Med. 1999 Mar; 6(3): 213-217. 